\title{
Cerita "Sunan Têmbayat" sebagai Sumber Penggubahan Motif Batik Ciri Khas Desa Jarum di Kecamatan Bayat, Kabupaten Klaten
}

\author{
Wisma Nugraha Christianto dan Rudy Wiratama \\ Program Studi Sastra Jawa, Departemen Bahasa dan Sastra, Fakultas Ilmu Budaya, \\ Universitas Gadjah Mada \\ Koresepondensi: krisnugraha@gmail.com
}

\section{Tim Pengabdian Masyarakat}

Wisma Nugraha Christianto, Rudy Wiratama, Akhmad Nugroho, Anung Tedjowirawan, Apriastuti Rahayu, Arsanti Wulandari, Daru Winarti, Djarot Heru Santosa, Hendrokumoro, R. Bima Slamet Raharja, Soeharto Mangkusudarmo, Sri Ratna Saktimulya, Sulistyowati, Sumarsih, Wiwien Widyawati Rahayu

\begin{abstract}
Tèmbayat, or well-known as Bayat in Klaten Regency is a region which has a rich tradition, religious and historical value according to Javanese perspective. One of its main factors is the presence of the saint Sunan Tèmbayat's graveyard site and some other shrines, supported by some folktales which have flourished there for generations. Bayat's geographical condition which lies on the karst land on the foot of Sewu Mountain can't make its society depend on agricultural sectors, so Bayat people nowadays are much known as entrepreneurs and craftsmen such as batik home industry. This article will show the results of "Pengabdian Kepada Masyarakat" (Social Responsibility Program) of Javanese Program of Language and Literature Department in Faculty of Cultural Sciences, Gadjah Mada University, which assisted the villagers of Jarum, Bayat county, Klaten Regency as one of prominent batik industrial centers. The main output of this program is to compose a new traditional-based batik pattern related with stories about Sunan Tèmbayat or Ki Agèng Pandhanaran as a local specialty through textual and contextual approaches on both written and oral literary sources.
\end{abstract}

Keywords: Folktale; Sunan Tèmbayat; batik pattern; composition; Klaten

\begin{abstract}
Abstrak
Wilayah Těmbayat atau yang lebih dikenal sebagai kecamatan Bayat di Kabupaten Klaten merupakan sebuah daerah yang kental dengan nilai tradisi, sejarah, dan religi di mata orang Jawa. Salah satu faktor pendukung dari fenomena ini adalah keberadaan situs sejarah makam Sunan Těmbayat dan beberapa petilasan lainnya di daerah ini, yang didukung dengan berbagai folklor yang meliputinya. Kondisi alam wilayah Bayat yang terdiri atas tanah kapur di kaki Pegunungan Sewu menjadikan masyarakatnya tidak dapat menggantungkan diri dari sektor pertanian sehingga orang-orang Bayat identik dengan kaum pedagang dan perajin, yang salah satunya dalam bidang industri batik yang kini bergerak menuju skala nasional. Artikel ini menguraikan hasil-hasil kegiatan Pengabdian Kepada Masyarakat Program Studi Sastra Jawa, Departemen Bahasa dan Sastra, Fakultas Ilmu Budaya, Universitas Gadjah Mada yang berbentuk pendampingan terhadap masyarakat Desa Jarum, Kecamatan Bayat, Kabupaten Klaten sebagai salah satu sentra industri batik yang menonjol. Luaran utama dari kegiatan ini
\end{abstract}


adalah terciptanya sebuah pola batik bercorak tradisi terkait dengan cerita "Sunan Těmbayat" atau "Ki Agěng Pandanaran" sebagai ciri khas setempat melalui pendekatan tekstual dan kontekstual terhadap sumber-sumber kesusastraan tertulis maupun lisan.

Kata kunci: Cerita rakyat; Sunan Tèmbayat; motifbatik; penggubahan; Klaten

\section{Pendahuluan}

Kecamatan Bayat yang termasuk dalam Kabupaten Klaten terletak di sudut selatan wilayah ini, berbatasan dengan Kabupaten Gunungkidul, Daerah Istimewa Yogyakarta di sebelah selatan, Kecamatan Cawas di sebelah timur, Kecamatan Wedi di sebelah barat, dan Kecamatan Trucuk di sebelah utara. Kecamatan Bayat terletak di daerah pegunungan kapur yang sejalur dengan wilayah Gunungkidul sehingga kenampakan wilayahnya berbukit-bukit dan kebanyakan warganya tidak menggantungkan diri dari bertani, tetapi berprofesi sebagai perajin mulai dari gerabah, berbagai macam peralatan dari batu, hingga kain batik.

Kecamatan Bayat dalam lintasan sejarah termasuk wilayah yang penting meskipun tidak terletak di pusat pemerintahan. Hal ini tampak dari berbagai cerita mengenai wilayah ini, yang kebanyakan terkait dengan tokoh Ki Ageng Pandanaran, Bupati Semarang yang mengundurkan diri dari kekuasaannya dan memilih untuk menyebarkan agama Islam di daerah ini hingga akhir hayatnya dengan gelar Sunan Tembayat. Selain adanya tokoh Sunan Tembayat, di daerah ini terdapat pula banyak tokoh lain yang berasal dari peralihan era Majapahit ke Demak Bintara, seperti Seh Sabuk Janur, Ki Ageng Becik, Seh Domba, Ki Ageng Konang, Ki Ageng Menang Lase, Ki Ageng Santri, Pangeran Menangkabo, dan Panembahan Jiwa. Kesemuanya memiliki cerita sendiri-sendiri dalam konteks peranannya sebagai pemimpin masyarakat lokal sejak zaman Demak, Mataram hingga pecahnya menjadi Surakarta dan Yogyakarta, yang menunjukkan bahwa daerah ini telah berusia tua dan memiliki tempat tersendiri dalam dinamika sejarah.

Kecamatan Bayat memiliki kurang lebih sepuluh sentra industri batik dengan kekhasan dan spesialisasi masing-masing. Beberapa sentra produksi batik di Kecamatan Bayat di antaranya adalah batik cap di Desa Beluk, batik tulis di Desa Jarum dan Kebon, serta batik tenun lurik di Desa Tegalrejo. Industri batik di Bayat telah bersifat turun-temurun dan menjadi salah satu daerah pemasok kain batik untuk pasar Klewer di Surakarta serta Beringharjo di Yogyakarta sejak beberapa dekade yang lalu. Batik yang dihasilkan di daerah Bayat memiliki banyak ragam, yakni mulai dari batik klasik yang memiliki ciri khas warna sogan untuk jarit atau nyamping, batik modern dengan warna-warna alam seperti nila (indigovera) dan motif-motif kontemporer untuk konsumsi fesyen serta selera pembeli internasional, sampai dengan batik kombinasi lurik dan batik di media selain kain seperti batik kayu, batik kulit, dan lain sebagainya.

Desa Jarum sebagai salah satu penghasil batik di Kecamatan Bayat termasuk sentra industri kerajinan yang maju jika dibandingkan dengan desa-desa lainnya yang juga memiliki beberapa produsen batik. Indikasi dari kemajuan tersebut adalah pencanangan Jarum sebagai Desa Wisata dan mendapat penghargaan di tingkat nasional (Miyono, perangkat desa Jarum dan pemilik galeri batik, wawancara tanggal 15 Juli 2019). Desa Jarum juga memiliki struktur pengelolaan UMKM (Usaha Mikro Kecil Menengah) yang 
lebih tertata daripada desa lainnya, dengan melibatkan berbagai pihak selaku stakeholder, baik dari Pemerintahan Desa maupun Kelompok Sadar Wisata (Pokdarwis) setempat. Dari segi permodalan, beberapa penggerak UMKM di Jarum berlaku aktif sehingga sampai saat ini, beberapa pengusaha batik di Jarum mendapatkan bantuan, baik dari sektor perbankan melalui skema kredit maupun melalui BUMN, dengan melibatkan diri sebagai industri binaan (wawancara dengan Susanna Dewi, pemilik galeri Batik Purwanti dan aktivis Pokdarwis Jarum, 15 Juli 2019).

Keberadaan industri batik di Bayat, khususnya di Jarum, memiliki beberapa versi. Setyo Harwanto dalam penelitiannya (2014) mencatat bahwa industri batik di Jarum telah ada sejak abad XVII dan dikenal sebagai pemasok berbagai jenis batik untuk keperluan Keraton. Pada tahun 1960-an, industri batik di Bayat mengalami masa keemasannya dan kemudian sempat merosot pada tahun 1970-an karena banyaknya warga yang merantau ke luar kota mencari penghidupan dengan pekerjaan lain. Pada tahun 1980-an, atas inisiatif beberapa pemuda, barulah industri batik di Bayat dihidupkan lagi, tetapi berpindah tempat dari Desa Beluk dan Paseban ke Desa Jarum (Harwanto, 2014:7). Hasil wawancara dengan Susanna Dewi, salah satu aktivis Pokdarwis setempat dan pemilik galeri batik "Purwanti" di Desa Jarum, memberikan cerita berbeda tentang asal mula industri batik di Jarum. Menurut Dewi, pada mulanya, para pembatik di Jarum adalah buruh sanggan, yakni orang-orang yang mengerjakan pesanan dari para saudagar batik di kota dengan cara membawanya ke rumah masing-masing. Kebanyakan pedagang batik yang menggunakan jasa buruh sanggan ini berasal dari Kota Surakarta sehingga tidak mengherankan jika batik Bayat memiliki ciri yang identik dengan batik corak Surakarta. Setelah tahun 1965, ketika terjadi paceklik dan industri batik di Surakarta mengalami kemerosotan, ibu dari Dewi, Purwanti, berinisiatif untuk merekrut mantan buruh sanggan yang diberhentikan dari pekerjaannya untuk melayani pesanan sendiri. Sejak saat itu, Jarum menjadi sentra industri batik mandiri kendati segmen pasar yang dituju masih tetap masyarakat Surakarta. Hal ini dapat dimengerti karena keterkaitan yang sangat erat antara industri batik Bayat dan Surakarta sehingga batik Jarum sampai sekarang masih identik dengan corak batik gaya Surakarta walaupun baru-baru ini juga muncul berbagai pola kreasi baru untuk melayani pasar yang lebih luas.

Transformasi Jarum dari desa industri ke desa wisata menuntut kreativitas para pembatik untuk merumuskan motif khas daerah setempat sebagai identitas lokal yang dapat dengan mudah dikenali oleh khalayak luas, baik nasional maupun internasional. Penggubahan motif khas Jarum juga menjadi suatu hal yang urgen karena dalam beberapa kesempatan desa ini memenangkan kompetisi desa wisata mulai dari tingkat kabupaten hingga nasional dan perajin setempat membutuhkan corak khusus dengan syarat (a) berpedoman pada tradisi, (b)memiliki kekhasan di bidang visual, dan (c)mempunyai makna filosofis yang dalam, sebagai upaya branding Desa Jarum sebagai destinasi wisata belanja sekaligus wisata budaya. Kebutuhan-kebutuhan masyarakat Jarum inilah yang akan dijawab oleh tim dari Program Studi Sastra Jawa, Departemen Bahasa dan Sastra, Fakultas Ilmu Budaya, Universitas Gadjah Mada melalui skema pendampingan, dalam upaya penggubahan motif batik identitas khas Jarum pada Pengabdian Kepada Masyarakat tahun 2019 ini. 


\section{Pedekatan Pelaksanaan Program}

Kegiatan Pengabdian Kepada Masyarakat dari Program Studi Sastra Jawa, Departemen Bahasa dan Sastra, Fakultas Ilmu Budaya, Universitas Gadjah Mada yang bertema pengembangan motif batik berdasarkan cerita rakyat di Jarum, Bayat, Kabupaten Klaten tahun 2019 dilaksanakan melalui beberapa tahap. Tahap-tahap tersebut diuraikan sebagai berikut.

\section{Tahap Pemetaan}

Pada tahap pemetaan, tim melakukan tiga kegiatan, yakni menerjunkan tim perintis untuk melakukan komunikasi pendahuluan dengan perangkat desa dan stakeholder, pengumpulan data tentang folklor yang ada di daerah Jarum, Kecamatan Bayat, serta kunjungan ke Makam Sunan Těmbayat atau Ki Ageng Pandhanaran di Paseban, Kecamatan Bayat, Klaten, sebagai upaya menelusuri versi-versi folklor yang terkait dengan tokoh ini. Kegiatan ini dilangsungkan pada Juli 2019.

\section{Tabap Pengerjaan}

Pada tahap ini, tim melakukan kajian pustaka terhadap sumber-sumber tertulis yang terkait dengan cerita Sunan Těmbayat, yang di antaranya terdapat pada Babad Jějěrira Selahardi koleksi Museum Sonobudoyo, Sěstradisuhul koleksi Pura Pakualaman Yogyakarta, serta tulisan Soewignya (1938) tentang biografi Ki Ageng Pandhanaran. Selain itu, tim juga mempertimbangkan beberapa cerita yang diperoleh dari masyarakat setempat, baik dalam bentuk legenda maupun pantang-larang yang berlaku dan masih dipercaya hingga kini, utamanya di daerah Bayat. Kegiatan ini dilangsungkan pada bulan Juli sampai Agustus tahun 2019.

\section{Tahap Sosialisasi}

Dalam tahap ini, tim melakukan sarasehan dan sosialisasi motif kepada para perajin batik yang tergabung di bawah Pokdarwis (Kelompok Sadar Wisata) setempat, yang kemudian dilanjutkan dengan proses produksi motif hasil gubahan dan pendampingan tim Pengabdian Kepada Masyarakat Program Studi Sastra Jawa, Departemen Bahasa dan Sastra, Fakultas Ilmu Budaya, Universitas Gadjah Mada. Kegiatan ini dilangsungkan pada Agustus 2019.

\section{Pelaksanaan Program}

Pelaksanaan kegiatan Pengabdian Kepada Masyarakat (PKM) yang diadakan oleh Program Studi Sastra Jawa, Departemen Bahasa dan Sastra, Fakultas Ilmu Budaya Universitas Gadjah Mada di Jarum, Kecamatan Bayat, Kabupaten Klaten dalam rangka pendampingan terhadap perajin batik setempat memiliki capaian akhir terciptanya motif batik khas Jarum yang sesuai dengan kebutuhan masyarakat setempat, yakni (a) berpedoman pada tradisi, (b)memiliki kekhasan di bidang visual, dan (c)mempunyai makna filosofis yang dalam. Oleh karena itu, dalam kegiatan ini dilakukan tiga tahap yang terdiri atas pengumpulan data, pengolahan data, serta sosialisasi dan penerapan.

Tahap pengumpulan data telah dilakukan pada 15 Juli 2019 dengan mengadakan kunjungan ke situs-situs sejarah terkait dengan Bayat dan Jarum, seperti makam Sunan 
Těmbayat di Desa Paseban dan Situs Mojoarum di Desa Jarum. Selain itu, tim juga mengumpulkan keterangan, baik dari pembatik, perangkat desa, maupun aktivis Pokdarwis setempat untuk mendapatkan gambaran tentang ragam motif dan teknik yang telah dikuasai oleh masyarakat setempat sebagai bahan pertimbangan untuk penyusunan konsep dan penuangannya dalam bentuk motif. Dari hasil pengumpulan data tersebut diketahui bahwa masyarakat Jarum berkeinginan untuk menampilkan motif yang memuat sejarah Bayat sebagai ciri khas, dengan menyertakan identitas Desa Jarum, yakni buah dari pohon maja-arum di dalamnya. Selain itu, masyarakat Jarum bermaksud untuk menuangkan motif tersebut dalam dua teknik, yakni teknik tulis untuk melayani pesanan premium dan teknik colètatau batik kombinasi dan cap untuk pangsa pasar yang menghendaki produk dengan harga yang lebih terjangkau. Masyarakat Jarum juga memiliki tiga jenis babaran atau teknik pewarnaan, yakni soga yang bernuansa kecokelatan untuk batik tradisional, sintetis menggunakan warna-warna cerah dan mencolok untuk bahan sandang, serta warna natural yang menggunakan bahan-bahan alami untuk pangsa pasar ibu kota dan internasional yang memiliki konsep back to nature atau "kembali ke alam" sebagai tren mode. Dalam tahap ini, tim mencoba mengusulkan tiga motif, yakni Gapura Panemut yang diambil dari ornamen pintu gerbang makam Sunan Tèmbayat, motif Dhomba-Kèwèl yang merupakan stilasi domba dan ular sebagai penjelmaan Seh Domba dan Sèh Kèwèl, serta motif Salah Tiga yang menggambarkan perjalanan Ki Agěng Pandhanarang ketika berada di Salatiga, dikepung oleh tiga orang perampok yang meminta harta benda yang dibawa Nyi Agěng Kaliwungu. Dua motif yang pertama mengalami penolakan dari pembatik setempat karena (a) motif pertama langsung dapat dikenali sebagai gapura makam Těmbayat dan jika dipakai sebagai isian batik, sebagian perajin masih mengkhawatirkan jika terkena walat atau tulah dari Ki Agěng Pandhanarang yang sampai sekarang masih dianggap memiliki keramat dan (b) motif Dhomba-Kèwèl dianggap terlalu realis dalam menggambarkan sosok fauna. Beberapa pembatik berpendapat bahwa sebagian pembeli sekarang menghindari motif fauna yang terlalu realis karena dianggap bertentangan dengan ajaran Islam. Motif Salah Tiga dapat diterima dengan baik pada tahap pengumpulan data karena dianggap lebih klasik. Akan tetapi, usulan dari Pokdarwis dan perangkat Desa Jarum agar selain memuat kisah perjalanan Sunan Těmbayat, motif ini juga hendaknya berisi cerita tentang Mojoarum sebagai cikal bakal daerah yang kelak akan memproduksinya. Berbekal usulan-usulan dari berbagai pihak tersebut, tim kemudian melakukan proses pengolahan data dengan melakukan penggubahan motif berdasarkan narasi yang diperoleh serta kebutuhan masyarakat setempat.

Tahap sosialisasi dan penerapan dilakukan di Desa Jarum dengan melibatkan kelompok perajin batik yang ada di daerah tersebut. Sebagai sarana sosialisasi, pada 5 Agustus 2019 diadakan sarasehan dan penyerahan pola motif tersebut kepada kelompok perajin batik di Desa Jarum, yang selanjutnya akan dikerjakan oleh masyarakat setempat dalam format batik tulis dan cap. Dalam sarasehan tersebut, tim mengusulkan nama motif gubahan baru ini kepada kelompok perajin, yakni Riris Pandhan Maja-arum. Kata riris berasal dari udan riris atau "hujan rintik-rintik", sementara pandhan dan majaarum diambil dari ragam hias berbentuk pohon pandan dan buah maja yang menjadi lambang Ki Agěng Pandhanaran serta Desa Jarum yang tertuang dalam motif tersebut.

Motif Riris Pandhan Maja-arum didesain oleh tim Program Studi Sastra Jawa untuk 


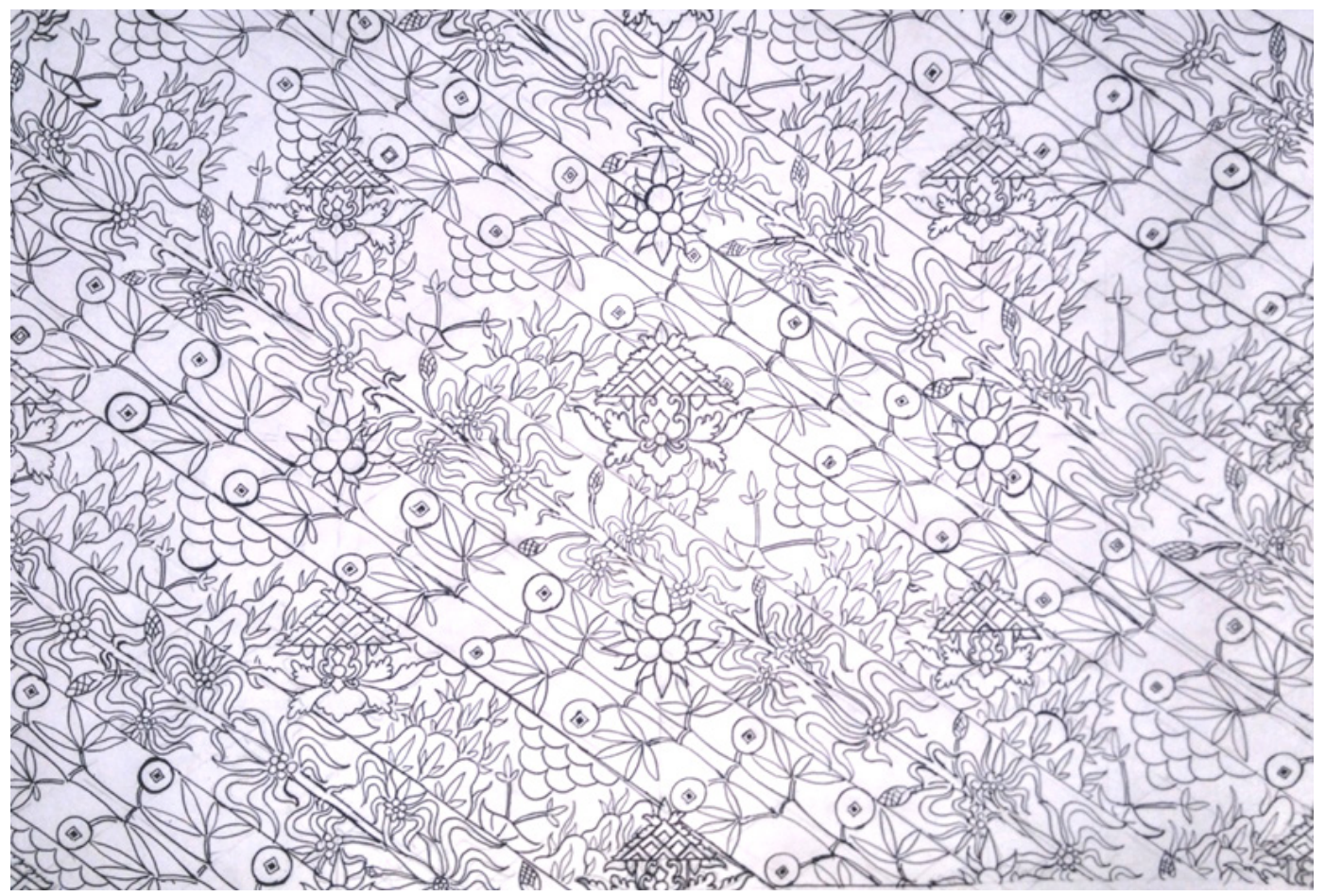

Gambar 1. Motif Riris Pandhan Maja-arum atau Udan Riris Pandhanarum, gubahan tim Pengabdian Kepada Masyarakat Program Studi Sastra Jawa, Departemen Bahasa dan Sastra, Fakultas Ilmu Budaya, Universitas Gadjah Mada sebagai hasil dari penelitian di Desa Jarum, Kecamatan Bayat, Kabupaten Klaten. Motif ini akan digunakan sebagai ciri khas batik produksi setempat. (Sumber: Rudy Wiratama)

dapat dikerjakan dengan metode tulis, kombinasi, dan cap dengan berbagai pilihan babaran atau pewarnaan sehingga dapat digunakan sebagai jarit atau kain penutup tubuh bagian bawah, sarung, selendang, maupun busana sehari-hari, baik dalam bentuk bahan sandang maupun pakaian jadi. Motif ini juga akan digunakan sebagai materi Pokdarwis setempat untuk menghadapi kompetisi Desa Wisata tingkat nasional yang akan diadakan pada akhir tahun 2019 mendatang.

\section{Refleksi Capaian Program}

Kegiatan Pengabdian Kepada Masyarakat yang dilangsungkan di Desa Jarum, Kecamatan Bayat, Kabupaten Klaten oleh tim dari Program Studi Sastra Jawa, Departemen Bahasa dan Sastra, Fakultas Ilmu Budaya, Universitas Gadjah Mada telah berhasil menggubah sebuah motif batik baru yang berbasis tradisi sebagai ciri khas lokal dan identitas industri batik setempat, yang selain digunakan untuk kepentingan kompetisi juga diproduksi secara luas untuk khalayak umum. Pencapaian ini bukanlah merupakan suatu titik akhir karena pada masa yang akan datang, untuk mempertahankan daya saing diperlukan kreativitas dan penemuan baru secara simultan (bdk. Sternberg dan Lubart, 1999:3). Oleh karena itu, pada masa yang akan datang, di samping melalui pendampingan, masyarakat Jarum juga dapat mengembangkan motif-motif baru secara mandiri dengan berbekal pengetahuan tentang kearifan lokal, cerita rakyat, dan sejarah yang banyak tersedia 
di daerah sekitar sebagai sumber inspirasi visual. Rekomendasi atau saran yang dapat diajukan oleh tim kepada masyarakat Jarum adalah agar para penggerak Pokdarwis tidak segan-segan untuk mencari sumber inspirasi secara intensif, tidak hanya melalui tradisi lisan populer, tetapi juga dapat berkonsultasi dengan tim untuk melakukan penggalian terhadap naskah-naskah kuno yang terkait dengan sejarah Desa Bayat, Jarum maupun Kabupaten Klaten pada umumnya, dam juga dalam rangka pengembangan ragam hias dengan memanfaatkan ornamen wědana rěnggan atau iluminasi dalam naskah-naskah kesusastraan koleksi perpustakaan di Surakarta maupun Yogyakarta sehingga pada masa yang akan datang dapat memperkaya perbendaharaan motif batik di daerah tersebut.

\section{Penutup}

Kegiatan Pengabdian kepada Masyarakat yang dilaksanakan oleh Tim Program Studi Sastra Jawa, Departemen Bahasa dan Sastra, Fakultas Ilmu Budaya, Universitas Gadjah Mada ini berangkat dari semangat pemberdayaan potensi lokal dengan menempatkan diri bukan sebagai tutor atau pembimbing yang terkesan menggurui, melainkan sebagai fasilitator yang mengakomodasi aspirasi dan kearifan yang ada di daerah Jarum, Kecamatan Bayat, Kabupaten Klaten untuk dapat dituangkan dalam bentuk motif batik yang menjadi sebuah ciri khas sentra kerajinan daerah ini. Tentu saja, hal ini tidak dapat dilandasi semangat waton béda (asal berbeda saja), tetapi juga perlu mempertimbangkan aspek tradisi, nilai kehidupan, dan narasi historis-kultural yang ada di daerah setempat, yang dalam hal ini adalah legenda tentang Maja Arum dan Sunan Těmbayat. Kedua legenda ini merupakan kebanggaan bagi masyarakat Bayat pada umumnya dan masyarakat Jarum pada khususnya karena narasi keduanya tidak lepas dari peran daerah Bayat dalam lintasan sejarah sebagai daerah "pusaka tanah Jawa" sejak zaman Sultan Hadiwijaya di Pajang hingga Dinasti Mataram Islam dan penerusnya.

Capaian kegiatan PkM ini, yakni penciptaan motif khas Jarum berbasis cerita rakyat dan legenda, telah terpenuhi lewat keberadaan motif Riris Pandhan Maja-arum, yang diterima dengan baik tidak hanya oleh satu perajin saja, tetapi oleh banyak kelompok perajin batik di Jarum. Beberapa perajin bahkan mengembangkan isian (isèn-isèn) dan teknik pewarnaannya masing-masing terhadap motif ini, yang menyebabkan berkembangnya motif ini di kalangan perajin. Tidak hanya itu, motif ini juga digunakan sebagai produk unggulan pada acara Pameran Batik Nusantara di Universitas Gadjah Mada pada Oktober 2019 serta Lomba Desa Wisata tingkat Provinsi Jawa Tengah yang saat itu Desa Jarum mendapat penghargaan sebagai juara pertama. Capaian-capaian ini diharapkan membuat warga Desa Jarum yang berprofesi sebagai perajin batik untuk dapat lebih kreatif dalam menggali, mengeksplorasi, dan bereksperimen dengan sumbersumber lisan serta tulisan tentang cerita rakyat dan sejarah yang ada di sekelilingnya secara intensif agar pada masa yang akan datang, identitas batik khas Jarum dapat lebih kuat lagi dengan adanya motif-motif baru yang tidak meninggalkan pakèm tradisi.

\section{Daftar Pustaka}

Anom, IGN. dkk. (1996). Hasil pemugaran dan temuan benda cagar budaya PJP I. Jakarta: Departemen Pendidikan dan Kebudayaan. 
De Graaf, H.J. (1989). Kerajaan-kerajaan Islam pertama di Jawa: kajian sejarah politik abad ke-15 dan ke-16. Jakarta: Grafitipers.

Harwanto, S. (2014). 'Kajian wisata seni budaya batik berwawasan lingkungan di desa Jarum, kecamatan Bayat, kabupaten Klaten, provinsi Jawa Tengah”. Tesis. Diajukan pada Program Pascasarjana, Institut Seni Indonesia, Yogyakarta.

Saktimulya, S.R. (2016). Naskah-naskah Skriptorium Pakualaman periode Paku Alam II 91830-1858). Jakarta: Kepustakaan Populer Gramedia.

Santoso, S. (2003). Babad Tanah Jawi (Galuh-Mataram). Surakarta: STSI Press.

Soedarsono. (t.t.). 'Naskah lama: sumber penelitian seni pertunjukan penuh misteri". Diktat Perkuliahan Mahasiswa Program Studi Pengkajian Seni Pertunjukan dan Seni Rupa, Sekolah Pascasarjana, Universitas Gadjah Mada, Yogyakarta.

Soewignja. (1938). Kyai Agěng Pandhanarang, Batavia: Volkslectuur-C.

Sternberg, R.J. dan Lubart, T.I. "Concepts of creativity" dalam Sternberg, R.J. (ed.). (1999). Handbook of creativity. New York dan London: Cambridge University Press. 